\title{
Contribution of a GATA4-Expressing Hematopoietic Progenitor Lineage to the Adult Mouse Endothelium
}

\author{
Rita Carmona ${ }^{1,2,3}$, Sandra Díaz del Moral ${ }^{1,2,3}$, Silvia Barrena ${ }^{1,2,3}$ (I) \\ and Ramón Muñoz-Chápuli 1,2,3,*(D) \\ 1 Department of Animal Biology, Faculty of Science, University of Málaga, 29071 Málaga, Spain; \\ rita@uma.es (R.C.); sandra.ddm@outlook.com (S.D.d.M.); silviabarrenagarcia@gmail.com (S.B.) \\ 2 Andalusian Center for Nanomedicine and Biotechnology (BIONAND), 29590 Málaga, Spain \\ 3 Institute of Biomedical Research of Málaga (IBIMA), 29010 Málaga, Spain \\ * Correspondence: chapuli@uma.es; Tel.: +0034-952-131853
}

Received: 30 March 2020; Accepted: 18 May 2020; Published: 19 May 2020

\begin{abstract}
Different sources have been claimed for the embryonic origin of the coronary endothelium. Recently, the potential of circulating cells as progenitors of the cardiac endothelium has also been suggested. In a previous study we have shown that circulating progenitors are recruited by the embryonic endocardium and incorporated into the coronary vessels. These progenitors derive from a mesodermal lineage characterized by the expression of Gata4 under control of the enhancer G2. Herein, we aim to trace this specific lineage throughout postnatal stages. We have found that more than $50 \%$ of the adult cardiac endothelium derives from the G2-GATA4 lineage. This percentage increases from embryos to adults probably due to differential proliferation and postnatal recruitment of circulating endothelial progenitors. In fact, injection of fetal liver or placental cells in the blood stream of neonates leads to incorporation of G2-GATA4 lineage cells to the coronary endothelium. On the other hand, labeling of the hematopoietic lineage by the stage E7.5 also resulted in positive coronary endothelial cells from both, embryos and adults. Our results suggest that early hematopoietic progenitors recruited by the embryonic ventricular endocardium can become the predominant source of definitive endothelium during the vascularization of the heart.
\end{abstract}

Keywords: circulating endothelial progenitors; coronary vessels; vascular growth; endothelium

\section{Introduction}

Endothelial cells primarily differentiate from angioblasts in a process called vasculogenesis. This process accounts for the formation of the earliest vessels in the embryo. Later, vascular growth is mainly achieved by angiogenesis, i.e., sprouting of pre-existing vessels. Vascular growth can also occur during development by recruiting angioblasts resident in the tissues [1] or circulating endothelial progenitor cells (EPC) [2]. The existence of circulating EPC has been well characterized in adults [3]. EPC can be mobilized from the bone marrow in response to injury and they can incorporate into the endothelium of damaged areas. However, there are few data concerning the existence of embryonic circulating endothelial progenitors and their putative participation in the vascularization of the mammalian embryo. For example, it is known that the murine fetal liver contains hematovascular progenitors with endothelial engraftment potential when transferred to the blood stream of newborns or adult conditioned recipients [4]. We have reported elsewhere that $20 \%$ of all the adult hematopoietic system in mice derives from progenitors where the GATA4 gene expression is driven by the specific mesodermal enhancer G2. Most of these progenitors arise in the placenta. Transplantation of fetal G2-GATA4 lineage cells into busulfan-treated newborns gives rise to endothelial cells at least in the liver [5]. More recently, it has been shown that an embryonic population of erythro-myeloid progenitors 
colonizes the embryo and contributes endothelial cells to the endothelium in multiple organs where they persist until adulthood [2]. This study estimated that $15 \%$ of the cardiac endothelium arises from the erythro-myeloid progenitors described by them. On the other hand, the existence of circulating endothelial progenitors in avian embryos has been demonstrated [6,7].

Thus, circulating progenitors constitute a potential source of endothelial cells for vascular growth during development, but their relevance for the establishment of the coronary circulation is still poorly known. Evidence for an origin of the coronary endothelium from different sources has been proposed in recent years, including subpopulations of proepicardial cells [8,9], ventricular endocardium [10], sinus venosus endocardium [11-13] and regionally distributed contribution of ventricular endocardium (ventral wall) and sinus venosus endocardium (dorsal wall) with a minor contribution of the epicardium [14]. The mosaic nature of the coronary endothelium is probably the only existing consensus in this regard, as it has been extensively discussed in recent reviews $[15,16]$. It is particularly debated if mesenchymal cells derived from the epicardium can contribute to the coronary endothelium. We have recently studied the developmental fate of four cell lineages related with the embryonic epicardium using the Cre-Lox technology [17]. In that report we showed that two epicardial-related cell lineages, revealed by the GATA5Cre and the cTnTCre drivers, accounted for about $4 \%$ of the cardiac endothelium along the gestation, probably representing the actual epicardial contribution to the coronary endothelium in embryos. The WT1 cell lineage is also related with the embryonic epicardium, where this gene is highly expressed, and its endothelial contribution reaches $7 \%$ at the end of gestation, probably due to de novo expression in non-epicardial-derived cells (EPDC). The G2-GATA4 ${ }^{\text {Cre }}$; R26R ${ }^{\text {eYFP }}$ model shows recombination in most of the epicardium and the EPDC. Thus, we expected a similar percentage of cardiac endothelial cells than the obtained with the other three models, but we found that this percentage increased sharply by midgestation from $5 \%$ to $20 \%$ of all the cardiac endothelium. Most surprisingly, many G2-GATA4 endothelial cells appeared frequently associated with the endocardium, far away from the epicardium. Given our observations on the presence of the G2-GATA4 lineage in the hematopoietic cells, we concluded that this increase was due to recruitment of G2-GATA4+ circulating endothelial progenitors into the endocardium. We also found evidence that these G2-GATA4+ endothelial progenitors proliferate faster than other endothelial cells, thus explaining the sharp increase of this population during gestation.

New observations performed on neonates and adults have shown that this increase in the participation of G2-GATA4 lineage endothelial cells in the cardiac vascularization continues postnatally giving rise to more than $50 \%$ of the cardiac endothelium in adults. We have also detected the presence of this lineage in the endothelium of other organs. In fact, this lineage appears as predominant in the adult kidneys. The aim of this study is to describe the contribution of the G2-GATA4 cell lineage to the endothelium of different adult organs. Our findings stress the importance of embryonic circulating endothelial progenitors in the definitive vascularization of the heart.

\section{Materials and Methods}

The animals used in our research program were handled in compliance with the institutional and European Union guidelines for animal care and welfare. The procedures used in this study were approved by the Committee on Ethics of Animal Experiments of the University of Malaga (procedure code 2018-0018). The adult mice used in this study were aged between three and six months.

The $\mathrm{Tg}\left(\mathrm{WT1} 1\right.$-cre)\#Jbeb (WT1 $\left.{ }^{\text {cre }}\right)$ mouse line has been used in previous studies to trace the WT1-expressing cell lineage or to delete specific genes in WT1-expressing cells [9,18-21]. For the generation of a G2-GATA4 ${ }^{\text {Cre }}$ line, a 642-base-pair fragment containing the minimal promoter from the mouse Mef2c gene was cloned into a plasmid containing the Cre complementary DNA and the SV40 splice and polyA signal sequence. An 817-bp fragment containing the conserved region, CR2, of the previously identified mouse G2 Gata4 enhancer was then cloned into the Cre expression vector to generate G2-GATA4 ${ }^{\text {Cre }}$ transgene [22,23]. Details of the GATA5 ${ }^{\text {Cre }}$ model have been published [24]. For cardiac 
troponin $\mathrm{T}$ lineage tracing we have used the $\mathrm{Tg}(\mathrm{Tnn}+2$-cre) $5 \mathrm{Blh}$ mouse strain. The $\mathrm{TnT}$ promoter drives early expression of Cre recombinase in the cardiomyocyte lineage beginning at E7.5 [25-27].

For lineage tracing studies, the murine lines carrying the Cre drivers (except for the GATA5 ${ }^{\text {Cre }}$ line) were crossed with homozygote Rosa26 ${ }^{\mathrm{EYFP}}$ (B6.129X1-Gt(ROSA)26Sor $\left.{ }^{\mathrm{tm} 1(\mathrm{EYFP}) \mathrm{Cos}} / \mathrm{J}\right)$ mice to generate permanent reporter expression in the lineage of Cre-expressing cells. The GATA5 ${ }^{\mathrm{Cre}}$ mice were crossed with a Gt(ROSA)26Sor ${ }^{\text {tm1Hjf }}$ reporter allele for Cre activity that expresses a non-toxic tandem-dimer red fluorescent protein.

Embryos were staged from the time point of vaginal plug observation, which was designated as the stage E0.5. Whole embryos were excised, washed in PBS and dissected to obtain the hearts or fixed in $4 \%$ fresh paraformaldehyde solution in PBS for 2-8 h. Fixed embryos were paraffin-embedded or washed in PBS, cryoprotected in sucrose solutions, embedded in OCT and frozen in liquid $\mathrm{N}_{2}$-cooled isopentane. Ten $\mu \mathrm{m}$ cryosections were stored at $-20^{\circ} \mathrm{C}$ until use.

\subsection{Analytical Flow Cytometry}

For flow cytometry analysis, dissected hearts from embryos or neonates were dissociated for $20 \mathrm{~min}$ at $37^{\circ} \mathrm{C}$ in pre-warmed $0.1 \%$ collagenase solution in cytometry buffer (PBS plus $2 \%$ fetal bovine serum and 10-mM HEPES) and homogenized by repeated pipetting. Adult hearts were finely minced and treated with Liberase TM (Merck KGaA, Darmstadt, Germany) for seven minutes at $37^{\circ} \mathrm{C}$. After homogenization by repetitive pipetting, the cell suspension was mixed with 4:1 vols of neutralizing buffer ( $5 \%$ sheep serum in DMEM), centrifuged and resuspended in cytometry buffer. In both cases, cell suspensions were washed in cytometry buffer and filtered through a 70- $\mu$ m nylon mesh. Then, cells were incubated on ice in the dark with the fluorochrome-conjugated antibodies. DAPI staining showed that less than $10 \%$ of the cells were damaged by this protocol.

Cells were analyzed in a FACS Verse flow cytometer. Data were analyzed with Kaluza Analysis software 2.1 (Beckman Coulter, Indianapolis IN 46268, USA) and displayed on tables as mean \pm standard error of mean. Negative controls (Cre-negative littermates) and isotypic antibodies allowed setting of the gates.

Details of the antibodies used for flow cytometry are provided in Table S1.

\subsection{Immunofluorescence and Confocal Microscopy}

Immunofluorescence was performed using routine protocols. Deparaffinized sections or cryosections were rehydrated in Tris-PBS (TPBS) and blocked for non-specific binding with SBT (16\% sheep serum, $1 \%$ bovine albumin, $0.1 \%$ Triton X-100 in TPBS). When biotinylated secondary antibodies were used, endogenous biotin was blocked with the Avidin-Biotin blocking kit from Vector. Single immunofluorescence was performed incubating the sections with the primary antibody overnight at $4{ }^{\circ} \mathrm{C}$, washing in TPBS and incubating with the corresponding fluorochrome-conjugated secondary antibody. Double immunofluorescence was performed by mixing both primary antibodies (rabbit polyclonal and mouse or rat monoclonal) and incubating overnight at $4{ }^{\circ} \mathrm{C}$. We then used a TRITC-conjugated and a biotin-conjugated secondary antibody, followed by $45 \mathrm{~min}$ incubation with Cy5-conjugated streptavidin. Nuclei were counterstained with DAPI (Sigma, D-4592).

Details of the antibodies used for immunofluorescence are provided in Table S1.

\subsection{Placenta/Fetal Liver Chimaeras}

Busulfan (1,4-Butanediol dimethanesulfonate, Merck KGaA, Darmstadt, Germany) is a myeloablative agent used to improve the efficiency of a hematopoietic graft in newborn mice $[5,28]$. Pregnant females were treated by intraperitoneal (i.p.) injection on days 17 and 18 of gestation with a 15 $\mathrm{mg}$ busulfan/Kg dose. Newborns at stage P1 are injected through the facial vein with cells suspended in $50 \mu \mathrm{L}$ of DPBS $+1 \%$ FCS $+1 \%$ penicillin/streptomycin $(\mathrm{P} / \mathrm{S})$. The cells were obtained from E11.5 G2-GATA4 ${ }^{\mathrm{Cre}}$; R26R ${ }^{\mathrm{EYFP}}$ embryos by mechanical disaggregation of fetal livers or collagenase treatment of placentas $\left(0.12 \%\right.$ collagenase in $\mathrm{Ca}^{2+}$ and $\mathrm{Mg}^{2+}$ free-PBS supplemented with $10 \%$ FCS and $1 \% \mathrm{P} / \mathrm{S}$, 
$30 \mathrm{~min}$ at $37^{\circ} \mathrm{C}$ ). After washing, the cell suspension was filtered, centrifuged and resuspended in the injection buffer. Two and four newborns were injected with fetal liver and placental cells, respectively.

\subsection{Labeling of the SCL Lineage}

The tamoxifen inducible HSC-SCL CreERT; R26R ${ }^{\text {EYFP }}$ [29] pregnant mice were used for permanent labeling of the early hematopoietic progenitors. Reporter expression was induced by the stage E7.5 by i.p. injection with tamoxifen (Merck KGaA, Darmstadt, Germany, T5648) dissolved in corn oil $(10 \mathrm{mg} / \mathrm{mL})$ at a dose of $0.1 \mathrm{mg} / \mathrm{g}$ body weight, together with $0.05 \mathrm{mg} / \mathrm{g}$ body weight of progesterone to reduce abortion risk. The embryos were fixed at the stage E14.5 and processed for flow cytometry and confocal microscopy. An adult mouse, four weeks old, induced at the stage E7.5, was also processed for flow cytometry of the heart.

\section{Results}

\subsection{The G2-GATA4 Cell Lineage Constitutes a Major Part of the Adult Cardiac and Kidney Endothelium}

We have compared the endothelial and non-endothelial adult fate of four cell lineages related with the embryonic epicardium. The results are shown in Table 1. The gating strategy and representative cytograms from all the lineages are shown in Figure 1. Endothelial cells were overrepresented in the cell suspensions after the enzymatic treatment.

The WT1 cell lineage contributes to $9.9 \%$ of the ventricular and $7.9 \%$ of the atrial endothelium in adult mice (Table 1 and Figure 2A). The GATA 5 and the cTnT lineages only account for $0.5 \%-1.5 \%$ of the cardiac endothelial cells. In contrast, the G2-GATA4 lineage represents $55.2 \%$ of the atrial and $53.3 \%$ of the ventricular endothelial cells. We compared this contribution of the WT1 and G2-GATA4 lineages to the cardiac endothelium with that from neonatal mice (Table 2). The percentage of ventricular endothelium from the WT1 lineage was similar to that found in adults $(10.4 \%$ versus $9.9 \%$ in the ventricle). The G2-GATA4 lineage contributed less to the neonatal ventricular endothelium than to the adult ventricular endothelium (34.5\% versus $53.3 \%$ ).

We also studied the contribution of the four lineages to the cardiac non-endothelial cells, basically fibroblasts and perivascular cells characterized by the expression of CD90 and CD140a/PDGFR $\alpha$ (Table 1). The G2-GATA4 and the GATA5 lineages were predominant in these populations, with percentages between $40 \%-65 \%$, while the WT1 and cTnT lineages showed lower frequencies, between $14 \%-40 \%$ in the ventricle. Despite the differences between the lineages (discussed below), these data confirm the significant contribution of the epicardial-derived cells to the stromal component of the adult heart.

We checked the frequency of endothelial cells from the WT1 and G2-GATA4 lineages in other organs obtained from adult mice (Table 2 and Figure 2). Endothelial cells from the WT1 lineage were less frequent in lung and liver than in the heart (4-6\% of all the endothelial cells), and they were virtually absent from the kidney endothelium. The G2-GATA4 lineage accounted for a moderate fraction of the lung $(15.6 \%)$ and liver $(9.9 \%)$ endothelium, but this percentage was predominant in the kidney $(86.7 \%)$. We also studied the contribution of the WT1 and G2-GATA4 lineages to the liver, lung and kidney endothelium of neonatal mice. The WT1 lineage increases moderately in the endothelium of lung and liver, but this lineage is virtually lacking in the endothelium of the neonatal kidney. The endothelial contribution of the G2-GATA4 lineage increases mildly in the lung and it does not increase in kidneys (where it already accounts for $92.7 \%$ of all endothelial cells in neonates) or liver.

The high presence of G2-GATA4 cell lineage in the endothelium of the adult heart, lungs and kidneys was confirmed by confocal microscopy (Figure 2B-D). 
Table 1. Contribution of the four lineages studied to the adult endothelium (CD31) and to the CD90 and CD140a (PDGFR $\alpha$ ) populations of the heart (mean \pm S.E.M.).

\begin{tabular}{|c|c|c|c|c|c|c|c|c|c|c|c|c|c|}
\hline \multirow{4}{*}{ Atrium } & \multirow{3}{*}{$\begin{array}{c}\text { Lineage } \\
\%\end{array}$} & \multicolumn{3}{|c|}{ WT1 } & \multicolumn{3}{|c|}{ G2-GATA4 } & \multicolumn{3}{|c|}{ GATA5 } & \multicolumn{3}{|c|}{ cTnT } \\
\hline & & CD31 & CD90 & CD140a & CD31 & CD90 & CD140a & CD31 & CD90 & CD140a & CD31 & CD90 & CD140a \\
\hline & & $\begin{array}{c}22.7 \pm 4.1 \\
(n=8)\end{array}$ & $\begin{array}{c}10.1 \pm 2.2 \\
(n=6)\end{array}$ & $\begin{array}{c}20.5 \pm 4.2 \\
(n=6)\end{array}$ & $\begin{array}{c}29.9 \pm 3.3 \\
(n=9)\end{array}$ & $\begin{array}{c}9.1 \pm 1.5 \\
(n=8)\end{array}$ & $\begin{array}{c}19.9 \pm 3.9 \\
(n=8)\end{array}$ & $\begin{array}{c}30.6 \pm 3.2 \\
(n=4)\end{array}$ & $\begin{array}{c}7.7 \pm 0.8 \\
(n=3)\end{array}$ & $\begin{array}{c}21.8 \pm 6.1 \\
(n=2)\end{array}$ & $\begin{array}{c}26.4 \pm 4.1 \\
(n=4)\end{array}$ & $\begin{array}{c}10.1 \pm 1.2 \\
(n=3)\end{array}$ & $\begin{array}{c}18.6 \pm 4.6 \\
(n=3)\end{array}$ \\
\hline & $\%$ YFP & $7.9 \pm 1.1$ & $23.3 \pm 4.3$ & $56.0 \pm 7.8$ & $55.2 \pm 2.8$ & $52.2 \pm 6.2$ & $\begin{array}{c}60.9 \pm \\
10.9\end{array}$ & $\begin{array}{c}0.67 \pm \\
0.16\end{array}$ & $50.3 \pm 6.8$ & $38.4 \pm 9.7$ & $\begin{array}{c}0.58 \pm \\
0.11\end{array}$ & $\begin{array}{c}20.4 \pm \\
0.71\end{array}$ & $18.9 \pm 8.1$ \\
\hline \multirow[t]{2}{*}{ Ventricle } & $\%$ & $\begin{array}{c}60.7 \pm 3.8 \\
(n=8)\end{array}$ & $\begin{array}{c}6.1 \pm 0.5 \\
(n=8)\end{array}$ & $\begin{array}{c}6.7 \pm 1.1 \\
(n=8)\end{array}$ & $\begin{array}{c}72.7 \pm 2.1 \\
(n=9)\end{array}$ & $\begin{array}{c}6.5 \pm 0.6 \\
(n=8)\end{array}$ & $\begin{array}{c}4.4 \pm 0.5 \\
(n=8)\end{array}$ & $\begin{array}{c}58.3 \pm 6.3 \\
(n=4)\end{array}$ & $\begin{array}{c}6.6 \pm 1.5 \\
(n=4)\end{array}$ & $\begin{array}{c}3.6 \pm 0.6 \\
(n=4)\end{array}$ & \multirow{2}{*}{$\begin{array}{c}60.6 \pm 4.0 \\
(n=4) \\
0.97 \pm \\
0.092\end{array}$} & $\begin{array}{c}6.8 \pm 1.0 \\
(n=4)\end{array}$ & $\begin{array}{c}6.9 \pm 0.8 \\
(n=4)\end{array}$ \\
\hline & $\%$ YFP & $9.9 \pm 0.7$ & $37.4 \pm 2.7$ & $31.4 \pm 4.7$ & $53.3 \pm 3.1$ & $57.4 \pm 6.8$ & $52.3 \pm 5.9$ & $1.6 \pm 0.74$ & $63.8 \pm 2.5$ & $38.7 \pm 4.1$ & & $35.1 \pm 6.6$ & $14.0 \pm 2.7$ \\
\hline
\end{tabular}



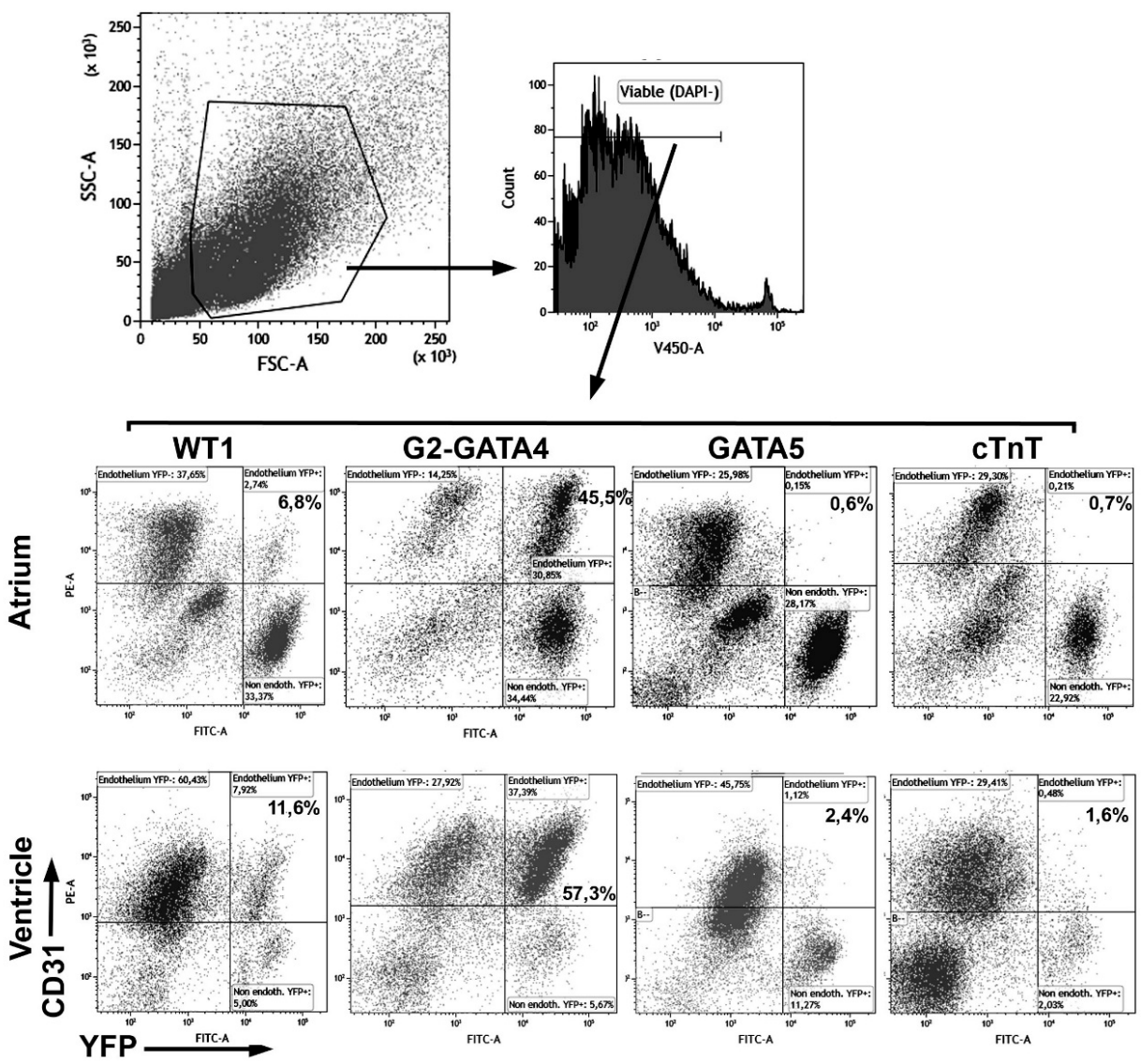

Figure 1. Representative cytograms of the contribution of the four lineages studied to the adult cardiac endothelium. Percentages on the cytograms refer to total viable cells (DAPI-negative) of the endothelial $(\mathrm{CD} 31+)$ subpopulations derived from each lineage. A major part of the endothelial cells in atrium and ventricle derives from a G2-GATA4 lineage, as detailed in Table 1.
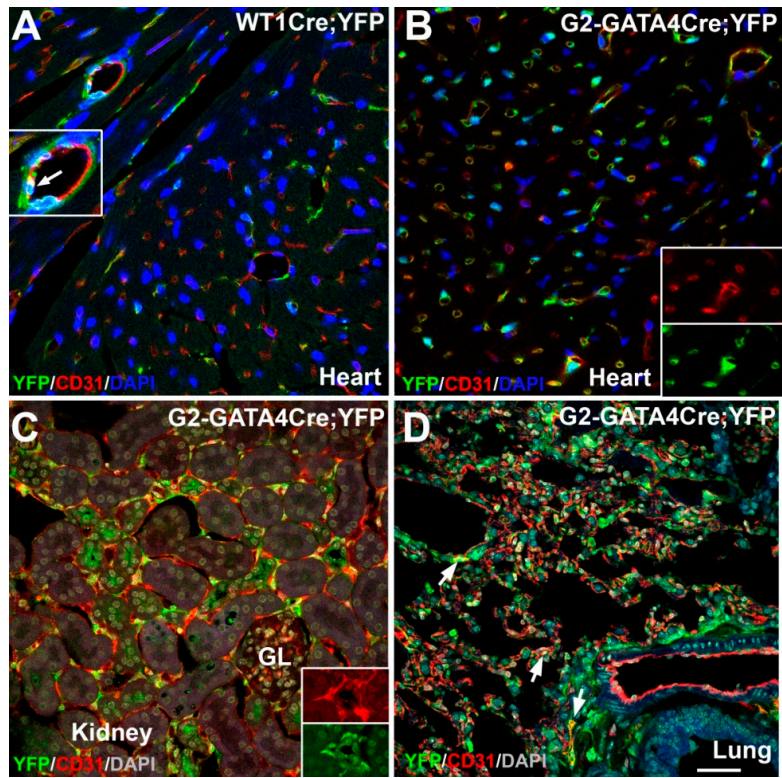

Figure 2. Localization of endothelial cells of the WT1 and G2-GATA4 lineages in adult heart, kidney and lung. In the heart, the WT1 lineage endothelium (A) is less abundant than the G2-GATA4lineage endothelium (B). Most of the kidney endothelium is also derived from the G2-GATA4 lineage (C), but this endothelium is less frequent in the lung (arrows in D). Inserts show higher magnification or separate channels to illustrate colocalization of markers. GL: glomerulus. Scale bar for all the figures: $50 \mu \mathrm{m}$. 
Table 2. Contribution of the WT1 and G2-GATA4 lineages to the endothelium of heart, lung, liver and kidneys (mean \pm S.E.M.).

\begin{tabular}{lccccc}
\hline & & Ventricle & Lung & Liver & Kidney \\
\hline \multirow{2}{*}{ WT1 Neonates } & \% CD31 & $\begin{array}{c}11.3 \pm 2.6 \\
(n=3)\end{array}$ & $\begin{array}{c}6.2 \pm 2.3 \\
(n=3)\end{array}$ & $\begin{array}{c}8.1 \pm 0.3 \\
(n=3)\end{array}$ & $\begin{array}{c}15.6 \pm 2.1 \\
(n=3)\end{array}$ \\
& $\%$ CD31+/YFP+ & $10.4 \pm 1.3$ & $2.9 \pm 0.9$ & $1.0 \pm 0.6$ & $0.03 \pm 0.03$ \\
\hline \multirow{2}{*}{ WT1 Adults } & \% CD31 & $\begin{array}{c}60.7 \pm 3.8 \\
(n=8)\end{array}$ & $\begin{array}{c}35.6 \pm 0.9 \\
(n=3)\end{array}$ & $\begin{array}{c}28.5 \pm 1.09 \\
(n=3)\end{array}$ & $\begin{array}{c}22.6 \pm 3.8 \\
(n=3)\end{array}$ \\
& \% CD31+/YFP+ & $9.9 \pm 0.7$ & $4.1 \pm 1.2$ & $5.6 \pm 1.5$ & $0.46 \pm 0.07$ \\
\hline \multirow{2}{*}{ G2-GATA4 Neonates } & \% CD31 & $17.7 \pm 1.6$ & $5.2 \pm 0.8$ & $8.9 \pm 2.3$ & $16.9 \pm 2.1$ \\
& $\%$ CD31+/YFP+ & $34.5 \pm 2.3$ & $10.8 \pm 1.4$ & $9.6 \pm 2.1$ & $92.7 \pm 1.0$ \\
\hline \multirow{2}{*}{ G2-GATA4 Adults } & \% CD31 & $72.7 \pm 2.1$ & $37.8 \pm 2.69$ & $34.5 \pm 5.49$ & $17.8 \pm 6.2$ \\
& \% CD31+/YFP+ & $(n=9)$ & $(n=5)$ & $(n=3)$ & $(n=3)$ \\
& & & $15.6 \pm 1.8$ & $9.9 \pm 4.3$ & $86.7 \pm 4.7$ \\
\hline
\end{tabular}

3.2. The G2-GATA4 Cell Lineage Contribution to the Cardiac Vasculature Starts During the Earliest Stages of Coronary Development and it is Related with Endocardium

We have described previously the recruitment of circulating G2-GATA4 lineage cells into the ventricular endocardium, and how this process increases the fraction of the cardiac endothelium derived from this lineage. We studied when this process starts. In early embryos (E11.5) it is possible to see the first G2-GATA4 lineage cells in the endothelial lining or circulating into the ventricular cavity (Figure 3A). These cells express GATA4 and frequently show a globular shape. In later stages, these G2-GATA4 lineage cells are far more abundant, and they appear into the intertrabecular sinusoids, where their GATA4 immunoreactivity has disappeared (Figure 3B, red arrowheads). Thus, two populations of G2-GATA4 lineage cells can be distinguished in the heart by midgestation, one delaminating from the epicardium (arrows in Figure 3B) and another one related with the endocardium (arrowheads in Figure 3B).
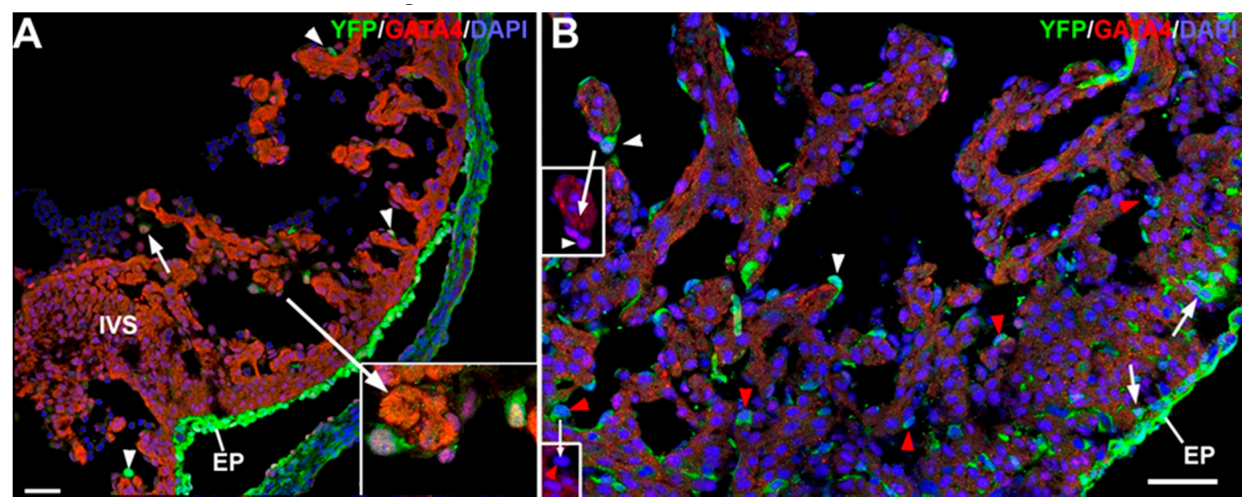

Figure 3. Localization of cells of G2-GATA4 lineage in the embryonic heart. (A) E11.5 embryo. Cells of the G2-GATA4 lineage expressing GATA4 can be seen in the circulation (arrow) and also incorporated into the ventricular endocardium (arrowheads and insert). The epicardium (EP) is also composed by cells of the G2-GATA4 lineage. (B) By stage E14.5, there are G2-GATA4 lineage cells in both ventricular endocardium (arrowheads) and subepicardium (arrows). White arrowheads show endothelial cells facing the ventricular lumen and expressing GATA4, while red arrowheads indicate abundant GATA4-negative endothelial cells into the intertrabecular sinusoids. Red channel (GATA4 expression) is shown in the inserts. Scale bars: $50 \mu \mathrm{m}$.

\subsection{The G2-GATA4 Cell Lineage Contribution to the Embryonic Endothelium of the Kidney Derives} from the Lateral Mesoderm

As described above, $92 \%$ of the kidney endothelium in neonates and $86 \%$ in adults derives from the G2-GATA4 lineage. We checked this percentage in kidneys of E14.5 embryos and we found that $80.0 \% \pm 2.1 \%(n=4)$ of the endothelium in this stage is also derived from the G2-GATA4 lineage (Figure 4). Thus, differently to that observed in the heart, the G2-GATA4 lineage accounts for the 
vascularization of the kidney from the earliest stages of their development, and the recruitment of circulating progenitors does not seem significant, as discussed below. Instead, angiogenesis from the lateral mesoderm adjacent to the metanephric primordium can account for the high frequency of G2-GATA4 progenitors. Figure S1 shows the ureteric buds in the metanephric primordium of an E12.5 embryo, revealing the abundance of endothelial cells from the G2-GATA4 in the adjacent lateral mesoderm.

\subsection{Early Hematopoietic Progenitors Contribute to the Coronary Endothelium}

Labeling of the hematopoietic lineage at the stage E7.5 (HSC-SCL ${ }^{\text {CreERT; R26R }}{ }^{\text {EYFP }}$ model) provoked that a fraction of the cardiac endothelium and cardiac hematopoietic cells became YFP+ by the stage E14.5 (Figure 5A). Namely, $2.6 \% \pm 0.4 \%$ of the CD $31+$ and $6.6 \% \pm 1.5 \%$ of the CD $45+$ cardiac cells were labeled $(n=8)$. In an adult mouse, 4 weeks old, also induced by the stage E7.5, we found $6.2 \%$ of the endothelial cells and $5.4 \%$ of the hematopoietic cells expressing the YFP reporter. However, in this mouse, we could not find any YFP+ endothelial cell in the kidney (Figure 5B). Thus, early hematopoietic progenitors can give rise to endothelial cells in the heart, but not in the kidneys.

\subsection{Embryonic G2-GATA4 Lineage Circulating Progenitors can be Recruited into the Endothelium in Postnatal Stages}

We next checked if putative circulating progenitors from the G2-GATA4 lineage can be recruited by the endothelium in postnatal stages. We injected liver or placental cell suspensions from E11.5 G2-GATA4Cre; EYFP embryos into the blood stream of neonatal mice. By this stage G2-GATA4 lineage hematopoietic progenitors can be found in both organs [5]. After 4 months, we found a number of endothelial cells in the heart, lung and kidneys (Figure 6), showing that the recruitment of circulating endothelial progenitors is still occurring in postnatal stages.
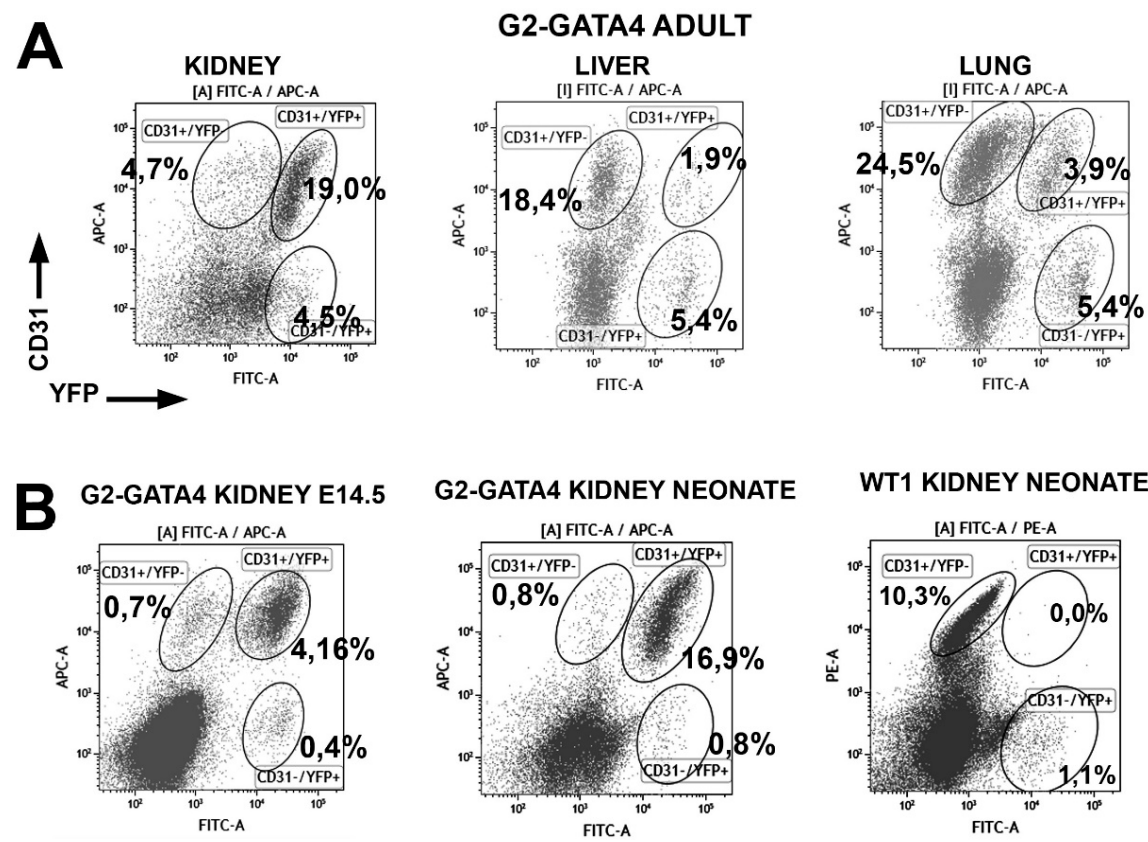

Figure 4. (A) Representative cytograms of G2-GATA4 lineage cells in kidney, liver and lungs of adults. (B) Representative cytograms of G2-GATA4 and WT1 lineage cells in kidneys of embryos and neonates. G2-GATA4 endothelial cells were predominant in kidneys of embryos, neonates and adults. However, there were no WT1-lineage endothelial cells in neonates. Percentages refer to total viable cells. 
A. Embryo, E14.5
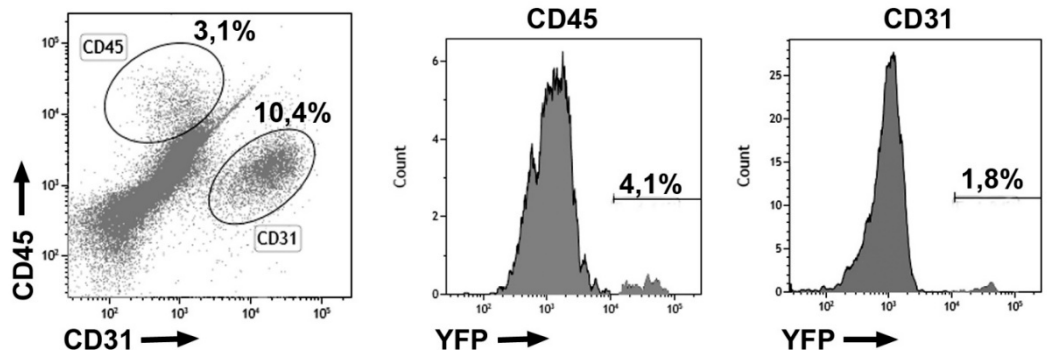

B. Adult
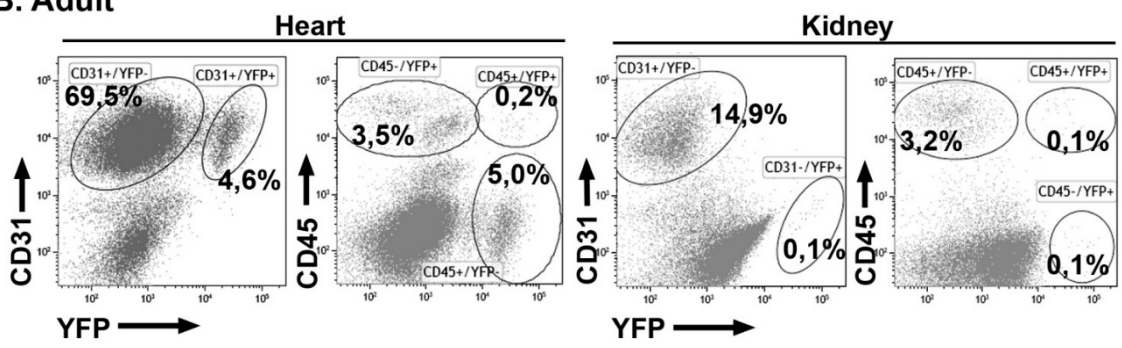

Figure 5. Representative cytograms of cardiac cells from the HSC-SCL ${ }^{\text {CreERT }}$ lineage (hematopoietic) induced at the stage E7.5. (A) E14.5 embryo. Some cardiac endothelial cells were YFP+, suggesting a hematopoietic origin. (B) Cardiac and kidney cells obtained from an adult mouse induced at the stage E7.5. Almost all the YFP+ cells in the heart were endothelial and they account for a fraction of all the cardiac endothelium. However, the kidney lacked YFP+ endothelial cells. Percentages refer to total cells.

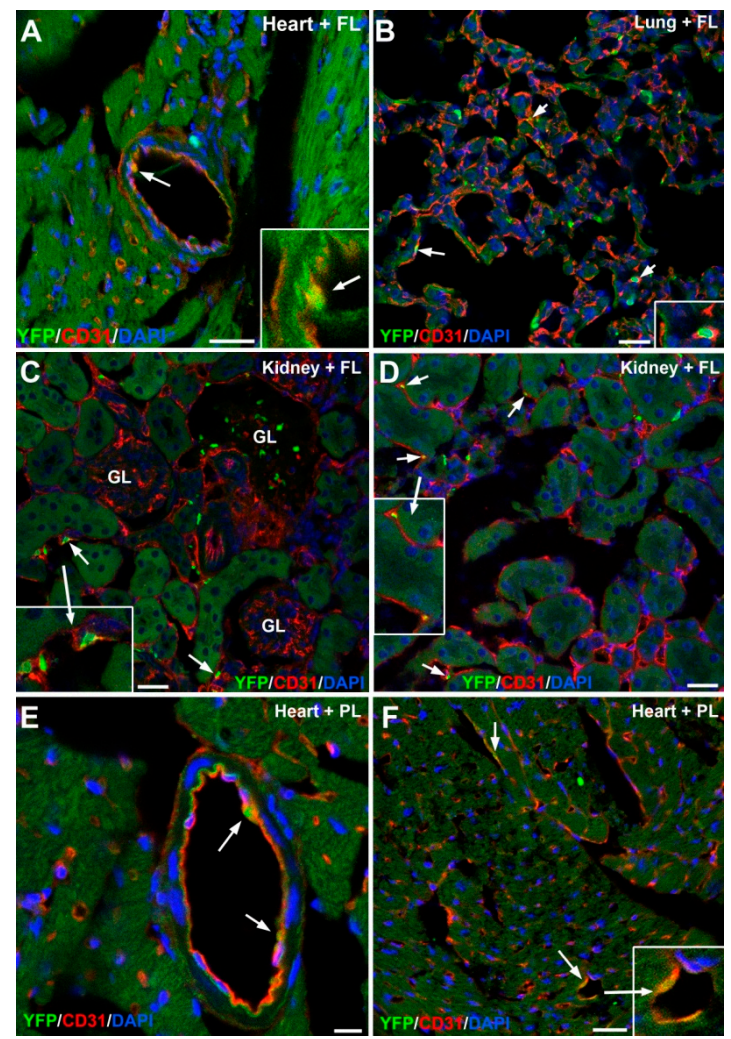

Figure 6. Representative images of adult organs from mice injected at the newborn stage with fetal

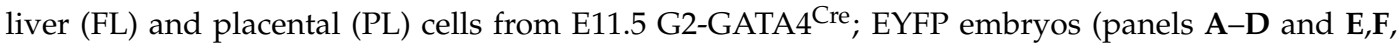
respectively). In the heart $(\mathbf{A}, \mathbf{E}, \mathbf{F})$, lung $(\mathbf{B})$ and kidney $(\mathbf{C}, \mathbf{D})$, endothelial cells were recruited into the endothelium four months after transplantation (arrows). The inserts show higher magnification images to illustrate colocalization of markers. Scale bars: $25 \mu \mathrm{m}$. except for $\mathrm{E}(10 \mu \mathrm{m})$. 


\section{Discussion}

Despite controversy concerning the different sources contributing to the coronary endothelium $[15,16]$, it is surprising that an extracardiac/circulating source has not considered until recently [2,17]. On the other hand, it is also remarkable that most studies considering different endothelial sources have tracked the lineages until mid- or late gestation-neglecting the possibility of further changes in the composition of the coronary endothelium in postnatal stages. We already published results that show that two of the usual lineage tracing systems were not reliable for following the fate of the epicardial derived cells [17]. WT1 is expressed de novo in some cardiac endothelial cells increasing slightly the frequency of this lineage in the cardiac endothelium from the $4 \%$ obtained with other lineage-tracing systems until $7 \%$ in late embryos. We have found now that in neonates this percentage rose to $10 \%$ and remained stable until the adult stages.

In contrast with our observations on the WT1 lineage, the contribution of the G2-GATA4 lineage to the cardiac endothelium reported in our previous work [17] increased from the stage E14.5 on, reaching $20 \%$ in late embryos. We explain the increase as a consequence of the recruitment of circulating endothelial progenitors. Endomucin expression allowed us to distinguish between these progenitors and the epicardial-derived angioblastic cells. We have shown herein that the contribution of the G2-GATA4 lineage to the cardiac endothelium also increases postnatally, from $34.5 \%$ in neonates to more than $50 \%$ in adults. In contrast, the actual epicardial contribution to the adult, as shown by the GATA5 and cTnT lineages is very small, less than $2 \%$. Furthermore, the early labeling of the hematopoietic lineage in the HSC-SCL ${ }^{\text {CreERT }}$ model [29] confirmed the incorporation of early hematopoietic cells to the cardiac endothelium. These results are surprising since they suggest that a major part of the adult coronary endothelium would derive from extracardiac/circulating progenitors recruited into the endocardium. However, we think that our observations are entirely congruent with previous reports on the participation of the ventricular endocardium in the coronary development $[10,14]$, since the circulating progenitors apparently incorporate into this endocardium and presumably acquire their phenotypic features.

The postnatal period is characterized by rapid growth of the coronary vasculature due to the rapid increase in cardiac size and performance [30]. We have observed during this period an increase of the G2-GATA4 lineage contribution from neonates to adults. A plausible explanation of this increase is a differential proliferation. We have shown that the endothelial cells from the G2-GATA4 lineage proliferate more than the rest of the endothelium in neonates [17]. The more recent incorporation of these presumably more immature endothelial cells to the vascular walls would explain their higher proliferation compared with the resident, mostly quiescent, endothelium. However, a specific study must be required to characterize potential transcriptomic differences between the G2-GATA4 lineage endothelium and other endothelial cells. A second explanation, not conflicting with the preceding one, is the postnatal recruitment of circulating progenitors. In fact, this possibility is suggested by our results. Injection of fetal liver or placental cells in neonates show that G2-GATA4 lineage cells can incorporate into the endothelium of several organs, included the heart. However, we cannot estimate how relevant is this putative source of endothelial cells in physiological conditions and what part of the increase recorded between neonates and adults can be explained by this process. Endomucin expression was not useful in adult mice to identify putative circulating progenitors, as it was in embryos [17]. Thus, a temporal study of the presence of endothelial progenitors in the circulation, from embryos to adult mice, would be required to respond to this issue.

We extended our study on the endothelial contribution of the G2-GATA4 lineage to other viscera and we were surprised by the high proportion of these cells in the kidney endothelium $(80 \%-92 \%$ in embryos, neonates and adults). In contrast, the contribution to the endothelium of other organs such as liver or lungs is moderate $(10 \%-15 \%)$, much smaller than that observed in the heart. We think that the striking abundance of endothelial cells from the G2-GATA4 lineage in the kidneys is not due to the recruitment of hematopoietic progenitors. In the kidneys, a high frequency of this lineage is recorded since the earliest stages of their development, and we have not found a significant increase in this frequency from neonates to adults. Furthermore, we could not find endothelial cells derived 
from hematopoietic progenitors in the adult kidneys, using the HSC-SCL ${ }^{\text {CreERT }}$ model, although other studies have found a small population of renal endothelial cells from hematopoietic origin when these mice are induced at the stage E6.5 [31]. In fact, we have found a small number of G2-GATA4 lineage endothelial cells in the adult kidneys after injection of fetal liver cells in neonates (Figure 6C,D).

The issue of the development of the kidney vascularization is highly controversial [32]. Compelling evidence of sprouting angiogenesis has been provided [33]. These authors describe how the metanephric mesenchyme is invaded by angiogenic sprouts from peripheric endothelial plexuses. This can be significant, since we have shown that these perirenal vessels are mainly composed of G2-GATA4 endothelial cells. Anyhow, the authors do not discard that resident angioblasts can contribute to the renal vasculature, as suggested by other studies (e.g., [34]). Thus, we think that hematopoietic progenitors from the G2-GATA4 lineage contribute to a major part of the adult endothelium of the heart—and to a minor part of the lung and liver endothelium — but they do not participate significantly in the kidney vascularization.

In summary, we think that more attention should be paid to the importance of circulating endothelial progenitors in the vascularization of the organs, both pre- and postnatally. In recent years, the high heterogeneity of the endothelial cells has been highlighted, and this heterogeneity could be relevant from the clinical point of view (see $[35,36]$ for a review). Endothelial cells could retain memory of their embryonic origin contributing in this way to their adult heterogeneity.

Supplementary Materials: The following are available online at http://www.mdpi.com/2073-4409/9/5/1257/s1, Figure S1: G2-GATA4 ${ }^{\text {Cre }}$;EYFP embryo, stage E12.5. The vascularization of the metanephric primordium (MN) is beginning. The early vessels inside and surrounding the metanephros contain many G2-GATA4 lineage endothelial cells (arrows). AO: aorta, ND: nephric duct; UB: ureteric bud, HL: hindlimb. Supplemental Table S1. Antibodies used in this study

Author Contributions: Conceptualization, R.M.-C. and R.C.; methodology, R.M.-C., S.D.d.M., S.B., R.C.; validation, S.D.d.M., S.B., R.C.; investigation, R.M.-C., S.D.d.M., S.B., R.C.; resources, R.M.-C. and R.C.; writing-original draft preparation, R.M.-C.; writing-review and editing, R.M.-C. and R.C.; supervision, R.M.-C.; project administration, R.M.-C. and R.C.; funding acquisition, R.M.-C. and R.C. All authors have read and agreed to the published version of the manuscript.

Funding: This research was funded by the Spanish Ministry of Science, Innovation and Universities/FEDER, UE under grant BFU2017-83907-P; Instituto de Salud Carlos III-TERCEL network under grant RD16/0011/0030; Consejería de Salud and Consejería de Economía y Conocimiento, Junta de Andalucía, under grants PC0066-2017/0034 and UMA18-FEDERJA-146, respectively.

Acknowledgments: The G2-GATA4 ${ }^{\mathrm{Cre}}$ murine line was generously provided by Dr. Anabel Rojas (CABIMER, Sevilla, Spain). We thank David Navas and Jessica Roman (SCAI, University of Málaga) for technical help with confocal microscopy. We also thank Auxiliadora López and Rosa Hernández for technical help with flow cytometry.

Conflicts of Interest: The authors declare no conflict of interest.

\section{References}

1. Brand-Saberi, B.; Seifert, R.; Grim, M.; Wilting, J.; Kühlewein, M.; Christ, B. Blood vessel formation in the avian limb bud involves angioblastic and angiotrophic growth. Dev. Dyn. 1995, 202, 181-194. [CrossRef]

2. Plein, A.; Fantin, A.; Denti, L.; Pollard, J.W.; Ruhrberg, C. Erythro-myeloid progenitors contribute endothelial cells to blood vessels. Nature 2018, 562, 223-228. [CrossRef]

3. Asahara, T.; Kawamoto, A.; Masuda, H. Concise review: Circulating endothelial progenitor cells for vascular medicine. Stem Cells 2011, 29, 1650-1655. [CrossRef]

4. Cañete, A.; Comaills, V.; Prados, I.; Castro, A.M.; Hammad, S.; Ybot-Gonzalez, P.; Bockamp, E.; Hengstler, J.G.; Gottgens, B.; Sánchez, M.J. Characterization of a fetal liver cell population endowed with long-term multiorgan endothelial reconstitution potential. Stem Cells 2017, 35, 507-521. [CrossRef]

5. Cañete, A.; Carmona, R.; Ariza, L.; Sánchez, M.J.; Rojas, A.; Muñoz-Chápuli, R. A population of hematopoietic stem cells derives from GATA4-expressing progenitors located in the placenta and lateral mesoderm of mice. Haematologica 2017, 102, 647-655. [CrossRef]

6. Caprioli, A.; Jaffredo, T.; Gautier, R.; Dubourg, C.; Dieterlen-Lièvre, F. Blood-borne seeding by hematopoietic and endothelial precursors from the allantois. Proc. Natl. Acad. Sci. USA 1998, 17, 1641-1646. [CrossRef] 
7. Pardanaud, L.; Eichmann, A. Identification, emergence and mobilization of circulating endothelial cells or progenitors in the embryo. Development 2006, 133, 2527-2537. [CrossRef]

8. Katz, T.C.; Singh, M.K.; Degenhardt, K.; Rivera-Feliciano, J.; Johnson, R.L.; Epstein, J.A.; Tabin, C. Distinct compartments of the proepicardial organ give rise to coronary vascular endothelial cells. Dev. Cell 2012, 22, 639-650. [CrossRef]

9. Cano, E.; Carmona, R.; Ruiz-Villalba, A.; Rojas, A.; Chau, Y.; Hastie, N.D.; Muñoz-Chápuli, R.; Pérez-Pomares, J.M. Proepicardial contribution to mammalian coronary endothelium patterns coronary blood vessels. Proc. Natl. Acad. Sci. USA 2016, 113, 656-661. [CrossRef]

10. Wu, B.; Zhang, Z.; Lui, W.; Chen, X.; Wang, Y.; Chamberlain, A.A.; Moreno-Rodriguez, R.A.; Markwald, R.R.; O'Rourke, B.P.; Sharp, D.J.; et al. Endocardial cells form the coronary arteries by angiogenesis through myocardial-endocardial VEGF signaling. Cell 2012, 151, 1083-1096. [CrossRef]

11. Red-Horse, K.; Ueno, H.; Weissman, I.L.; Krasnow, M.A. Coronary arteries form by developmental reprogramming of venous cells. Nature 2010, 464, 549-553. [CrossRef] [PubMed]

12. Tian, X.; Hu, T.; Zhang, H.; He, L.; Huang, X.; Liu, Q.; Yu, W.; He, L.; Yang, Z.; Zhang, Z.; et al. Subepicardial endothelial cells invade the embryonic ventricle wall to form coronary arteries. Cell Res. 2013, 23, 1075-1090. [CrossRef] [PubMed]

13. Zhang, H.; Pu, W.; Li, G.; Huang, X.; He, L.; Tian, X.; Liu, Q.; Zhang, L.; Wu, S.M.; Sucov, H.M.; et al. Endocardium minimally contributes to coronary endothelium in the embryonic ventricular free walls. Circ. Res. 2016, 118, 1880-1893. [CrossRef] [PubMed]

14. Chen, H.I.; Sharma, B.; Akerberg, B.N.; Numi, H.J.; Kivelä, R.; Saharinen, P.; Aghajanian, H.; McKay, A.S.; Bogard, P.E.; Chang, A.H.; et al. The sinus venosus contributes to coronary vasculature through VEGFC-stimulated angiogenesis. Development 2014, 141, 4500-4512. [CrossRef]

15. Tian, X.; Pu, W.T.; Zhou, B. Cellular origin and developmental program of coronary angiogenesis. Circ. Res. 2015, 116, 515-530. [CrossRef] [PubMed]

16. Sharma, B.; Chang, A.; Red-Horse, K. Coronary artery development: Progenitor cells and differentiation pathways. Annu. Rev. Physiol. 2017, 79, 1-19. [CrossRef]

17. Carmona, R.; Barrena, S.; López Gambero, A.J.; Rojas, A.; Muñoz-Chápuli, R. Epicardial cell lineages and the origin of the coronary endothelium. FASEB J. 2020, 34. [CrossRef]

18. Del Monte, G.; Chamorro, J.; Guadix, J.A.; MacGrogan, D.; Burch, J.; Muñoz-Chápuli, R.; Pérez-Pomares, J.M.; de la Pompa, J.L. Differential notch signalling in the epicardium is required for cardiac inflow development and coronary vessel morphogenesis. Circ. Res. 2011, 108, 824-836. [CrossRef]

19. Wessels, A.; van den Hoff, M.J.; Adamo, R.F.; Phelps, A.L.; Lockhart, M.M.; Sauls, K.; Briggs, L.E.; Norris, R.A.; van Wijk, B.; Pérez-Pomares, J.M.; et al. Epicardially derived fibroblasts preferentially contribute to the parietal leaflets of the atrioventricular valves in the murine heart. Dev. Biol. 2012, 366, 111-124. [CrossRef]

20. Casanova, J.C.; Travisano, S.; de la Pompa, J.L. Epithelial-to-mesenchymal transition in epicardium is independent of Snail1. Genesis 2013, 51, 32-40. [CrossRef]

21. Cano, E.; Carmona, R.; Muñoz-Chápuli, R. WT1-expressing progenitors contribute to multiple tissues in the developing lung. Am. J. Physiol. Lung Cell Mol. Physiol. 2013, 305, 322-332. [CrossRef] [PubMed]

22. Rojas, A.; De Val, S.; Heidt, A.B.; Xu, S.M.; Bristow, J.; Black, B.L. Gata4 expression in lateral mesoderm is downstream of BMP4 and is activated directly by Forkhead and GATA transcription factors through a distal enhancer element. Development 2005, 132, 3405-3417. [CrossRef] [PubMed]

23. Delgado, I.; Carrasco, M.; Cano, E.; Carmona, R.; García-Carbonero, R.; Marín-Gómez, L.M.; Soria, B.; Martín, F.; Cano, D.A.; Muñoz-Chápuli, R.; et al. GATA4 loss in the septum transversum mesenchyme promotes liver fibrosis in mice. Hepatology 2014, 59, 2358-2370. [CrossRef] [PubMed]

24. Merki, E.; Zamora, M.; Raya, A.; Kawakami, Y.; Wang, J.; Zhang, X.; Burch, J.; Kubalak, S.W.; Kaliman, P.; Izpisua Belmonte, J.C.; et al. Epicardial retinoid $\mathrm{X}$ receptor alpha is required for myocardial growth and coronary artery formation. Proc. Natl. Acad. Sci. USA 2005, 102, 18455-18460. [CrossRef]

25. Jiao, K.; Kulessa, H.; Tompkins, K.; Zhou, Y.; Batts, L.; Baldwin, H.S.; Hogan, B.L. An essential role of Bmp4 in the atrioventricular septation of the mouse heart. Genes Dev. 2003, 17, 2362-2367. [CrossRef]

26. Eley, L.; Alqahtani, A.M.; MacGrogan, D.; Richardson, R.V.; Murphy, L.; Salguero-Jimenez, A.; Sintes Rodriguez San Pedro, M.; Tiurma, S.; McCutcheon, L.; Gilmore, A.; et al. A novel source of arterial valve cells linked to bicuspid a ortic valve without raphe in mice. Elife 2018, 7, e34110. [CrossRef] 
27. Mifflin, J.J.; Dupuis, L.E.; Alcala, N.E.; Russell, L.G.; Kern, C.B. Intercalated cushion cells within the cardiac outflow tract are derived from the myocardial troponin T type 2 (Tnnt2) Cre lineage. Dev. Dyn. 2018, 247, 1005-1017. [CrossRef]

28. Peake, K.; Manning, J.; Lewis, C.A.; Barr, C.; Rossi, F.; Krieger, C.J. Busulfan as a myelosuppressive agent for generating stable high-level bone marrow chimerism in mice. Vis. Exp. 2015, 1, e52553. [CrossRef]

29. Göthert, J.R.; Gustin, S.E.; Hall, M.A.; Green, A.R.; Göttgens, B.; Izon, D.J.; Begley, C.G. In vivo fate-tracing studies using the Scl stem cell enhancer: Embryonic hematopoietic stem cells significantly contribute to adult hematopoiesis. Blood 2005, 105, 2724-2732. [CrossRef]

30. Tomanek, R.J.; Zheng, W. Role of growth factors in coronary morphogenesis. Tex. Heart Inst. J. 2002, 29, 250-254.

31. Hu, Y.; Li, M.; Göthert, J.R.; Gomez, R.; Sequeira-Lopez, M.L. Hemovascular Progenitors in the Kidney Require Sphingosine-1-Phosphate Receptor 1 for Vascular Development. J. Am. Soc. Nephrol. 2016, 27, 1984-1995. [CrossRef] [PubMed]

32. Mohamed, T.; Sequeira-Lopez, M.L.S. Development of the renal vasculature. Semin. Cell Dev. Biol. 2019, 91, 132-146. [CrossRef] [PubMed]

33. Munro, D.A.D.; Hohenstein, P.; Davies, J.A. Cycles of vascular plexus formation within the nephrogenic zone of the developing mouse kidney. Sci. Rep. 2017, 7, 3273. [CrossRef]

34. Halt, K.J.; Pärssinen, H.E.; Junttila, S.M.; Saarela, U.; Sims-Lucas, S.; Koivunen, P.; Myllyharju, J.; Quaggin, S.; Skovorodkin, I.N.; Vainio, S.J. CD146(+) cells are essential for kidney vasculature development. Kidney Int. 2016, 90, 311-324. [CrossRef] [PubMed]

35. Aird, W.C. Phenotypic heterogeneity of the endothelium: I. Structure, function, and mechanisms. Circ. Res. 2007, 100, 174-190. [CrossRef]

36. Aird, W.C. Phenotypic heterogeneity of the endothelium: II. Representative vascular beds. Circ. Res. 2007, 100, 158-173. [CrossRef]

(C) 2020 by the authors. Licensee MDPI, Basel, Switzerland. This article is an open access article distributed under the terms and conditions of the Creative Commons Attribution (CC BY) license (http://creativecommons.org/licenses/by/4.0/). 